\title{
The Real World of the Decentralized Autonomous Society
}

\author{
J.Z. Garrod \\ Carleton University, Ottawa, Canada, jzgarrod@gmail.com
}

\begin{abstract}
Many commentators have been quick to note the revolutionary potential of Bitcoin 2.0 technology, with some even believing that it represents the coming of a decentralized autonomous society in which humans are freed from centralized forms of power and control. Influenced by neoliberal theory, these individuals are implicitly working on the assumption that 'freedom' means freedom from the state. This neglects that the state can also provide freedom from the vagaries of the market by protecting certain things from commodification. Through an analysis of (1) class and the role of the state; (2) the concentration and centralization of capital; and (3) automation, I argue that the vision of freedom that underpins Bitcoin 2.0 tech is one that neglects the power that capital holds over us. In neglecting this power, I claim that this technology might be far more dystopian than we comprehend, making possible societies that are commodities all the way down.
\end{abstract}

Keywords: Bitcoin, Blockchain, Ethereum, Capitalism, State

Acknowledgement: Many thanks to editors Andreas Roos and Vasilis Kostakis, as well the two anonymous reviewers for their comments and suggestions.

"But where change exists, so too do possibilities"- Murray Bookchin $(2015,54)$.

Although it is still in its early stages, many commentators have been quick to note the revolutionary potential of the second wave of blockchain innovation. Bitcoin 2.0 technology, as it has come to be called by many, refers to the combination of the blockchain (which is a type of distributed database made popular by Bitcoin) with user-programmable smart contracts. By combining the blockchain with smart contracts, the technology can theoretically be used to create any number of social contracts, such as: nongeographic countries (complete with taxes, benefits, and voting), transnational lending programs, universal basic income schemes, marriage contracts-the works (Meltzer 2014; Schneider 2015; Volpicelli 2015). In fact, IBM and Samsung have already used this technology to create a washing machine that orders its own detergent, a proof of concept for the coming "Internet of Things" (Higgins 2015).

For many, however, the most interesting aspect of this technology is the ability to create decentralized autonomous organizations (DAOs), which are essentially corporations in which the management function is automated by code, and the human element is removed (Buterin 2014). While some have expressed fear that the widespread application of DAOs might engender the rise of a Terminator-style Skynet (De Filippi 2014a), many believe that it represents the coming of a "decentralized autonomous society" (DAS) in which humans are 'freed' from centralized institutions of power and control (Alchemi 2015; Frank 2015; Patron 2014; Robinson 2015; Thorp 2015).

Outside of concerns over legality and regulation (De Filippi 2014b; De Filippi and Belli 2012), however, there has been little investigation as to how the DAS might function in the real world. While there are many grand claims, there seems to be little understanding of the wider social context in which the DAS is embedded. Indeed, for all the fear of these technologies, there is little work problematizing their relationship to capitalism, and whether they might in fact help strengthen capital's control over the social world-and, perhaps, by proxy, transform the very institutions of power and control that support capitalist social relations.

Consequently, what I would like to do in this paper is to explore the real world of the DAS, to explore the ideas and theories about social life that underpin these technologies, and 
some of the real world issues that might problematize this utopian vision. The impetus for this project stems from two Massey Lectures: The Real World of Democracy, by C.B. Macpherson, and The Real World of Technology, by Ursula M. Franklin. ${ }^{1}$ In the former, Macpherson $(1965,4)$ explores the rival ideas of democracy (communist, Third World, Western-liberal variants) and their impacts on one another. Years later, Franklin $(1999,2)$ proposed a similar strategy, but in respect to technology. Her reasoning was that technology, like democracy, includes ideas and practices; it includes myths and various models of reality. And like democracy, technology changes the social and individual relationships between us. It has forced us to examine and redefine our notions of power and accountability. Against the idea that technology is apolitical, Franklin argued that it was something that has a considerable impact on issues of justice, fairness, and equality. In combining these two approaches, what I want to get across is that is important to compare what is said about something, and how that something might work in the real world; more often than not, the two are incompatible. And in the case of the DAS, I believe there are very significant contradictions between what is said about this type of society, and the model of reality that underpins it.

In what follows, I argue that by adhering to a neoliberal subjectivity, some supporters of the DAS have an obscured vision of: (1) class and the role of the state; (2) the concentration and centralization of capital; and (3) the role of automation. As I hope to make clear, the vision of freedom that seems to underpin Bitcoin 2.0 tech is one that neglects very significant forms of power and coercion; in particular, the power that capital holds over us in both organizing the structure of our lives, and informing our idea of what it means to be human. In neglecting these other forms of power, I claim that the DAS might be a far more dystopian development than its supporters comprehend, making possible societies that are, as Fraser $(2014,5)$ calls them, "commodities all the way down."

Admittedly, my comments and reflections are anticipatory, as little of what is discussed has come to pass, nor is it likely to come to pass in exactly the way in which l've presented it. There are real issues of scalability, infrastructure, and regulation that must first be overcome before Bitcoin 2.0 tech can be widely adopted in the manner that DAS proponents suggest (Higgins 2015; Scott 2014). As de Sousa Santos $(2004,241)$ notes, however, a sociology of emergences is one that inquires "into the alternatives that are contained in the horizon of concrete possibilities." By taking account of the "knowledge, practices and agents" (Ibid) involved in the development of new technologies, it becomes possible to "identify therein the tendencies of the future (the Not Yet) upon which it is possible to intervene so as to maximize the probability of hope vis-à-vis the probability of frustration" (Ibid). Consider this, then, my normative strategic intervention into the development of new types of societies. By offering some suggestions as to how we might better use these technologies to secure and mediate the commons (both digital and material), I conclude by arguing that there exists the possibility to create a more sustainable-and possible-future for all.

\section{Bitcoin and Bitcoin 2.0 Technologies}

While the future of Bitcoin is still uncertain, it is important to briefly overview its origins so as to put these new developments into context. Despite multiple attempts to create digital money, developers had never been able to get around the double spending problem. Because digital money is just information, the same token could feasibly be duplicated and spent more than once. Attempts to solve this problem in the digital world inevitably came up with the same means of solving it in the real world: a centralized authority (such as a bank) that can verify whether or not a token has been spent-i.e. a centralized form of trust. This not only created a significant weakness in the system as a result of having a single breaking point, but it also relied on exactly what developers had been trying to move away from.

Enter Satoshi Nakomato. In the aftermath of the 2008 financial crisis, Nakamoto-a mysterious figure known only by his presumed pseudonym—solved this problem. In "Bitcoin: A Peer-to-Peer Electronic Cash System," Nakamoto (2008) not only revealed Bitcoin, but also

\footnotetext{
${ }^{1}$ In Canada, the Massey Lectures are an annual five-part series of lectures given by a notable scholar.
} 
its central innovation: the blockchain. ${ }^{2}$ The blockchain is a public ledger of transactions that can be broadcast to the entire network and subsequently verified by a network of decentralized computers running Bitcoin software. This not only solved the double spender problem, but also provided the framework for other software programs that wished to move away from institutions of centralized trust.

In 2009, the Bitcoin network went live with the launch of the first open source Bitcoin client, and the release of the first bitcoins. ${ }^{3}$ Since then, Bitcoin has had a tumultuous journey that has included incredible volatility, market crashes, and government seizures (Vigna and Casey 2015). Although the currency continues to be used primarily for niche purposes (e.g., speculation and black market exchange) it has created a wider awareness of the potential of digital currencies. For instance, Ben Bernanke (as cited in Perlberg 2013, par. 3), the former Chairman of the Federal Reserve, has written that such currencies "may hold long-term promise, particularly if the innovations promote a faster, more secure and more efficient payment system." More recently, the Bank of Canada has said that it may look into issuing its own digital currency, and the Greek government has also suggested this strategy as one means of escaping from the current eurocrisis (Kang 2014; Mason 2015). While some institutions, such as the People's Bank of China, have banned their banks from handling bitcoins, the likely trajectory is the emergence of a "specific licensing category for bitcoin businesses" (Buterin, as cited in Osborne 2014). What is clear, however, is that what began as an experiment is now a part of the global public consciousness-helped, of course, by a market capitalization of billions of dollars. ${ }^{4}$

Despite Bitcoin's popularity, the blockchain remains the central innovation. And from this innovation there have been a number of subsequent developments. Often referred to as the second wave of blockchain innovation-or simply, Bitcoin 2.0 technologies-these new technologies have attempted to extend the functionality of the blockchain by combining it with smart contracts. Created by Nick Szabo (1997, par. 2), smart contracts are essentially digital contracts that are enforced automatically by a set of computer protocols. The simplest example is that of a vending machine:

\begin{abstract}
the machine takes in coins, and via a simple mechanism, which makes a freshman computer science problem in design with finite automata, dispense change and product according to the displayed price. The vending machine is a contract with bearer: anybody with coins can participate in an exchange with the vendor. The lockbox and other security mechanisms protect the stored coins and contents from attackers, sufficiently to allow profitable deployment of vending machines in a wide variety of areas.
\end{abstract}

In many ways, Bitcoin 2.0 tech is simply a digital version of this same phenomenon. Sitting on top of the blockchain, the software ensures that the transaction is fulfilled (whatever it may be), and engages the appropriate response (see below for examples). While multiple projects have attempted (or are attempting) some variant of this combination (e.g. Mastercoin, Counterparty, Maidsafe, Storj, Supernet, Gems, Eris Industries and SWARM), Ethereum has received the most attention. Developed by Vitalik Buterin, what distinguishes Ethereum from other Bitcoin 2.0 tech is that it "is an open source platform for smart contracts built on top of block chain technology" (Kosner, 2014, para. 5). Rather than adding new features to the block chain, Ethereum simply allows users to code their own decentralized applications (or Dapps).

By enabling users to program their own Dapps, Ethereum intends to "decentralize control of the Internet and anything connected to it, redistributing real-world power accordingly" (Frank 2015, 26). Encompassing a number of diverse applications such as finance (banking, payments, crowdfunding), sharing economies (Uber and AirBnB-like platforms), communications (social networks, email), reputation systems (credit rating, seller ratings), governance,

\footnotetext{
${ }^{2}$ This paper is often referred to as the Bitcoin white paper.

${ }^{3}$ Following standard practice, the capitalized version of Bitcoin refers to the technology, whereas the lower-case version of bitcoin refers to the currency.

${ }^{4}$ According to coinmarketcap.com at the time of writing, the market capitalization for bitcoin was $\$ 3,295,647,158$.
} 
and possibly more, Ethereum could have a massive impact on the future of economic development, and the shape of the global economy. Indeed, as De Filippi and Mauro (2014, par. 19) note, Ethereum is to the political system what Bitcoin is to the financial system: "if Bitcoin was designed as a decentralized alternative to counteract corruption and inefficiency of the monetary system, Ethereum constitutes a decentralized alternative to the notion of the organization per se."

Although it is still early days for Ethereum, things seem promising. In 2014, Buterin not only received a $\$ 100,000$ fellowship from PayPal co-founder and venture capitalist Peter Theil, but also won the World Technology Network award, beating out the likes of Mark Zuckerberg (creator of Facebook) in the IT software category (Hajdarbegovic 2014). More importantly, perhaps, is that IBM and Samsung chose Ethereum as one of three protocols for their proof of concept for ADEPT (Autonomous Decentralized Peer-to-Peer Telemetry), or an 'Internet of Things' powered by the blockchain. ${ }^{5}$ In their draft paper, they demonstrate how "a humble washer can become a semi-autonomous device capable of managing its own consumables supply, performing self-service and maintenance, and even negotiating with other peer devices both in the home and outside to optimize its environment" (as cited in Higgins 2015, par. 9).

\section{The Decentralized Autonomous Society}

While the prospect of a washing machine that can order its own detergent is intriguing, the true draw of Ethereum is its potential to remake the social world. The central institution that makes this possible is the decentralized autonomous organization, or DAO. As the name suggests, DAOs are essentially digital organizations that manage themselves: "long-term smart contracts that contain the assets and encode the bylaws of an entire organization" (Buterin 2014, par. 2). Depending on how they are structured, certain members of the DAO might be able to spend its funds, or modify its code. ${ }^{6}$

Buterin (2013, par. 2) has described DAOs as an attempt to extend the logic of the industrial revolution upwards. Where that revolution allowed us to "start replacing human labour with machines," it only automated the bottom half of the equation, "removing the need for rank and file manual labourers." DAOs are thus an attempt to see if it is possible to "remove management from the equation, instead." With such technology, it becomes possible for selfdriving cars to autonomously make micro-payments to each other for the right-of-way, or to share data plans via mesh networks, making much of the internet infrastructure unnecessary (Pollen 2013). ${ }^{7}$

\footnotetext{
${ }^{5}$ BitTorrent was chosen for file sharing, Ethereum for smart contracts, and TeleHash for peer-to-peer messaging.

${ }^{6}$ The methods by which funds are allocated, explains Buterin (2014, under "Decentralized Autonomous Organizations"), "could range from bounties, salaries to even more exotic mechanisms such as an internal currency." While this vision is one in which the DAO is essentially a digital replication of the corporation (with dividend-receiving shareholders and tradeable shares), Buterin (2014, under "Decentralized Autonomous Organizations") notes that there exists the possibility for alternative models, such as one in which "all members have an equal share in the decision making and require $67 \%$ of existing members to agree to add or remove a member."

${ }^{7}$ Buterin (2015) gave a more in-depth view at this future in a talk given at the Swiss Institute of New York: "You wake up, and see that $\$ 17.27$ was automatically deducted from your primary wallet, as you had authorized to happen every day, to pay the rent for your apartment; if you canceled the authorization, then, after a warning period, ownership in the land-registry contract would automatically transfer back to the landlord, and the door lock would no longer recognize signatures signed by your smartphone's private key as valid for letting you in. Of course, your landlord is bound by the same restrictions. If he shuts off his account that pays the local government $\$ 6.60$ land-value tax per day, then he loses ownership and the contract automatically switches over so you are renting from the government instead. The government itself is simply a large decentralized organization, and you can see in real time the $\$ 6.60$ moving on the blockchain and eventually getting into an account to pay for a medical-research program trying to extend the human lifespan from 170 years to 230 . The Internet that you are using to access this information is based on a decentralized and incentivized mesh-networking platform; you paid $\$ 0.0009$ to access the information, but your laptop also earned $\$ 0.0014$ transmitting other people's packets at the same time. You get into your Mastercar self-driving car to go to work (originally, all self-driving cars were made by Google, but Master Corporation, a decentralized autonomous entity that automatically uses a combination of futarchy and liquid democracy to determine how the company should spend its funds each day, proved that its governance mechanism was so efficient that it overtook Google on some core services within three years, and altMastercorps took over most of its other operations). You get in, and Mastercar runs a optimized version of the $A^{*}$
} 
For many true believers, however, smart contracts, blockchains, and the DAOs that might stem from them, are the building blocks of something much bigger: the decentralized autonomous society (DAS). While there are competing versions of this possible future, the predominant theme is a society in which technological development has disrupted the centralized and hierarchal forms of the nation-state system. ${ }^{8}$ In this society math, perfect information, and market mechanisms are supposedly able to solve the problem of organizational politics by removing humans from politics altogether.

Viewed as inherently corruptible creatures, the thinking goes that it is far more sensible "to base a future economy on the mathematical laws of the universe, outside the grasp of human error and manipulation" (Patron 2014, 102). ${ }^{9}$ Through DAOs, it is claimed, we might be able to augment human autonomy by automating the governance of all organizations, since DAOs can run "without any human involvement under the control of an incorruptible set of business rules" (Larimer 2013, par. 2). And since the code simply runs itself, these DAOs could run forever, making politics a simple problem of engineering.

Inherent in this view is the idea that political elites have too much power, and are a hamper on freedom. Billionaire Peter Thiel, for instance, writes that he no longer believes "that freedom and democracy are compatible" (as cited in Frank 2015, 27). Perhaps it could exist, "he imagined, in cyberspace, in outerspace, or on high-seas homesteads, where individualists could escape the 'terrible arc of the political." Similar remarks have been made by Roger Ver, the prominent Bitcoin investor, who argues that such technologies "will prevent governments from being able to just print money at will and then use that to buy tanks and guns and bombs to murder people around the world" (as cited in Dodd 2015, par. 4). While not all cryptographers share these views, Karlstrøm $(2014,29)$ notes that there has always been "a strong current of libertarian sentiments in the discussions about cryptography." Indeed, the popular economist Paul Krugman (2014, par. 1) has confessed that his own uneasiness with Bitcoin stems from the fact that it is "intimately tied up with libertarian anti-government fantasies."

Many, however, claim that these anti-government fantasies are unrealistic. More likely, claims Kosner (2014), is that DAOs intermingle with other, more traditional, centralized organizations, with each focusing on what it scales best to (Kosner, 2014). This point is echoed by De Filippi and Mauro (2014, par. 22) who suggest that it is more plausible to see a future in which "decentralized organizations with distributed models of governance, independent legal systems, or perhaps even autonomously governed communities . . . compete with both governments and corporations."

Such points seem to insinuate that we do not need to fear the libertarian fantasies wrapped up with Bitcoin 2.0 tech. Indeed, Buterin (2014) himself even titled one of his blog posts, "DAOs are not scary." This does little to alleviate my fears, however. While I agree that

search algorithm (for which James Wilbur automatically got a bounty of $\$ 782,228$ worth of MSC from the Master Contract) to determine the optimal path to your primary workplace. Given that your self-tracking app has detected that you value your own time (or, rather, the delta between time spent in a car versus time spent at home or work) at an average of $\$ 14.18$ per hour, the Mastercar's algorithm chooses a route that takes an extra eleven minutes in order to avoid road tolls and also on the way moves a shipment from one side of the city to the other. You drive out, and thirty minutes later you have spent $\$ 1.04$ on electricity for your car, $\$ 1.39$ on road tolls, but receive a reward of $\$ 2.60$ for moving the shipment over. You arrive at work-a location which is a hybrid living/working space where 'employees' of five different alt-versions of Master Corporation are spending most of their time, except that you chose to live at home because you have a family. You then get to work, running simulations of a proposed new scalability algorithm for the now community/DAO-driven Ethereum 6.0."

${ }^{8}$ Perhaps channeling Castells (2010), "The Fundamental Thesis Of The Network Society" provides one example: "1. Widespread social and economic change only happens once a solid technological foundation evolves to make it sustainable. 2. Globally distributed and decentralized technologies have emerged that achieve superior results with respect to centralized and hierarchal ones. 3. These unstoppable technologies undermine and disrupt the Nation State's supporting pillars. The resulting socioeconomic organization is the Network Society."

${ }^{9}$ In talking about Ethereum, Buterin tells Frank $(2015,36)$ that it is rather naïve to trust "corruptible humans and opaque institutions with concentrated power. Better to formalize our values forthrightly in code." Similarly, a firm named Colony (2015) that is in the process of creating a DAO interface (where DAOs are referred to as colonies) states: "Colonies are kind of like companies, except instead of being managed by fallible individuals, Colony harnesses the wisdom of the crowd using $\mathrm{Al}$ to make sure that the right things get done by the right people, at the right time." 
it is unlikely that DAOs will immediately overtake our existing forms of social organization, I am more concerned with the way in which these technologies reflect the contemporary thinking about the self and the wider society in which that self is constructed. For instance, the idea that politics is a simple problem of engineering is one that is underpinned by an image of the human as inherently selfish, greedy, and ultimately, corruptible. DAS supporters are thus beginning "from the assumption that there is no trust and no community, only individual economic agents acting in self-interest" (O'Dwyer, 2015, par. 15).

As many scholars have demonstrated, however, this image of the individual is as much a social construct as the traits that are ascribed to it (Burkitt, 2008; Elias, 2000; Macpherson, 2010; Teeple, 2004). Indeed, as Durkheim $(1973,80)$ notes, in earlier societies "so small a place is given to individual personality [...] not because it has been restrained or artificially suppressed," but "because, at that moment of history, it did not exist." While modern forms of individuality started to emerge from the $14^{\text {th }}$ century onwards, it is incredibly important to hammer home the point that there is no essential human nature, and that pre-modern peoples "thought of themselves as, not individuals but members of ranks or orders or communities" (Macpherson, 1965, 7). ${ }^{10}$

The reason for hammering this point home is that the idea that humanity is constituted by selfish monads plays a significant ideological role in sustaining capitalism. As early as 1732 , Bernard Mandeville (2007) was writing about how the personal characteristics associated with the pursuit of profit—greed, selfishness, competition, etc.-are healthy personal traits that benefit the social system; hence, the subtitle for his book: The Fable of the Bees: or, Private Vices, Public Benefits. Written as a counter to feudal property, it expressed the coming of a new age, and with it a new set of governing personal characteristics: "what was seen in the old view as the source of self-centredness, private interest, and corruption is now the driving force of a free and equal society" (Taylor, 2004, 151). Later works of the $20^{\text {th }}$ century, such as Rand's (1964) The Virtue of Selfishness, or the film, Wall Street, in which Gordon Gecko's character makes famous the phrase, "greed is good" (Stone, 1987) fulfil the same function: they promote an ideological consistency insofar as it concerns the individual as an isolate, and the particular characteristics that are viewed as being 'natural' to the self. ${ }^{11}$ If the ideas of cooperation, social justice, socialism, empathy, altruism, etc., are assumed to be alien to the human spirit, why try to create a socialist system that is contrary to human nature? Why try to help other humans (and non-humans) if our nature is all about helping only ourselves?

In what follows, I want to extend this line of critique more broadly, to explore some other real world issues that complicate the utopian claims made by DAS supporters on the basis of our (supposedly flawed) human nature. As I hope to demonstrate, it is only by neglecting some significant realities of the capitalist mode of extraction that this technology can be understood as a liberating-and not dystopian-force. By recognizing the ways in which this neglect might set us up for catastrophe, however, I argue that we have the capacity to reorient these technologies so as to use them to secure and mediate a variety of common properties, for the benefit of all.

\section{Class and the Role of the (Digital) State}

To begin, it is important to note that one of the most significant absences from any discussion about the DAS is the notion of class and its relationship to the state. While there is lots of talk about getting rid of centralized institutions of power, there seems to be little under-

\footnotetext{
${ }^{10}$ Similarly, Simmel $(1971,217)$ also writes: "The general European consensus is that the era of the Italian Renaissance created what we call individuality. By this is meant a state of inner and external liberation of the individual from the communal forms of the Middle Ages, forms which had constricted the patterns of his life, his activities, and his fundamental impulses through homogenizing groups."

${ }^{11}$ As Teeple $(2005,21)$ notes: "The citizens of liberal democracies are easily convinced that the concept of human being is simply a matter of self-relatedness because it reflects the central element of their reality. That is, the principles of their daily lives are based on contractual, self-interested relations that define the system in which they live and that must be followed if they are to maintain their material existence. The concept merely takes as human the character of exchange relations in capitalist society."
} 
standing of how or why those institutions came to exist in their centralized form in the first place.

This lack of understanding stems from the above-mentioned view that capitalism is a natural and inevitable result of our human nature (also referred to as the commercialization model of economic development). ${ }^{12}$ The line of thinking can be traced back to the classical political economists who thought that the development of capitalism was simply a result of our innate "propensity to truck, barter, and exchange" (Smith 2001, 16). Noting that different forms of exchange have been present throughout human history, they concluded that the development of capitalism must have been a result of the lifting of the various impediments to exchange. ${ }^{13}$

As pointed out by Marx (1991), however, this view is one that merely reads the character of private property back into the nature of the self. ${ }^{14}$ In doing so, the commercialization model completely neglects the actual history of the transition of capitalism (the 'so-called primitive accumulation') in which the power of the state was used by an emerging capitalist class to abolish feudal property relations, separate peasant labourers from their common lands, and introduce capitalist rationality (The Ecologist 1993; Marx, 1991; Macpherson, 2010; Polanyi 2002).

More recently, neoliberal thinkers have used the same model to justify privatization, open markets, and deregulation. Milton Friedman $(1962,12)$, for example, argues that competitive capitalism is the only means by which humans can resolve the basic problem of social organization-"how to co-ordinate the economic activities of large numbers of people"-without resorting to forms of coercion. Much like his intellectual forebears, however, Friedman fails to take into account "the coercion involved in the separation of capital from labour, or the possible mitigation of this coercion by the regulatory and welfare state" (Macpherson 1973, 147). While the welfare state was no doubt a class compromise, emerging to resist the widespread popular support for socialism in the post-war period, it managed to protect (for a time, at least) wholly new forms of common property in education, health care, housing, and so on, that greatly increased the living standards of millions of citizens in advanced capitalist countries (Reich, 1964).

By following the same flawed neoliberal logic, DAS supporters tend to believe that by removing the state from the equation and creating a society that consists strictly of digital exchange relations that we will enter into an epoch of more freedom and liberty. Indeed, as Finley (2014, par. 17) notes, "next-gen crypto-platforms paint a very attractive picture of our online future, one where users are in control, not governments or big companies." Beginning from a neoliberal subjectivity, the thinking goes that in a society in which political or social intervention is restricted so as to allow the total commodification of society (i.e., the transformation of all things into exchangeable private property), that we are much more free since we have the freedom to enter into any sort of exchange relation we desire. ${ }^{15}$

Of course, this is outside of the function of the code itself, which as Scott (2014, par. 42) notes, is a sort of "techno-leviathan" that mirrors Hobbes' thinking about the state. Because humans are thought to be inherently corruptible (and brutish and mean and nasty), we must necessarily exchange some of our freedom for security. ${ }^{16}$ Instead of relying on actual people

\footnotetext{
12 The commercialization model of economic development is the belief that capitalism emerged as a result of the build-up of commercial wealth. It includes scholars from a variety of theoretical perspectives including worldsystems theorists, classical and neoclassical economists, Weberian historical sociologists, and some Marxist scholars. For more, see Wood (2002).

${ }^{13}$ As Wood $(2002,11)$ notes: "The most common way of explaining the origin of capitalism is to presuppose that its development is the natural outcome of human practices almost as old as the species itself, which required only the removal of external obstacles that hindered its realization. This mode of explanation, or non-explanation, which has existed in many variants, constitutes what has been called the 'commercialization model' of economic development, and this model is arguably still the dominant one."

${ }^{14}$ Critiquing Bentham for making the same mistake, Marx $(1991,759)$ writes: "With the driest naiveté he assumes that the modern petty bourgeois, especially the English petty bourgeois, is the normal man."

${ }^{15}$ As Scott (2014, par. 41) notes, conservative libertarians tend to believe that "if only hard property rights and clear contracting rules are put in place, optimal systems spontaneously emerge."

${ }^{16}$ Interestingly, a similar thesis is put forth by Freud (2010) in Civilization and Its Discontents, albeit in a different way.
} 
to perform this function, however, the code is utilized as "a defined crypo-sovereign whose rules we can contract to."17 As Scott (2014, par. 43) accurately notes, this "appeals to those who believe that powerful institutions operate primarily by breaching property rights and contracts."

In reality, however, powerful institutions are not used to break contracts, but rather, to secure those contracts, which reflect ruling class power. ${ }^{18}$ The idea that one can simply decentralize the law completely neglects the function of law within capitalist societies. The state is not an unnatural force that confronts a natural market, but rather, an abstraction that we use to describe the political form of the relations of class dominance in various times and places, with the law itself being one particular mechanism for enforcing those relations. In the most general terms, the state is that complex of institutions that maintains the dominance of the ruling classes; defends existing property relations from basic change; and ensures that all other classes are kept in subjection. ${ }^{19}$ The nation-state, on the other hand, is a historically specific form of state that emerged alongside the rise of capitalism and the capitalist class. ${ }^{20}$ In most cases, the institutions of pre-existing monarchical states were merely reoriented to protect private property instead of feudal property. Through this process (which itself was the result of class struggle) the nation-state became the ultimate guarantor of property relations within the newly bounded territorial spaces achieved earlier by the various monarchies at the Treaty of Westphalia (Wood 2002).

In viewing the government and state as part and parcel of 'crony capitalism' and not capitalism itself, DAS supporters ignore the state's role in both securing the conditions for capital to exist (i.e., the so-called primitive accumulation), and the historical defence of wealth (Winters 2011). And it is only by ignoring this role that they can imagine a future stateless capitalist society as the most extreme vision of freedom. In reality, that world would likely be characterized by extreme inequality, poverty, and private authority resting on the ownership of capital: a form of "distributed capitalism" as Kostakis and Giotitsas (2014) put it, in which peer-to-peer infrastructures are utilized to accumulate and secure capital.

And we haven't even begun to speak about the class relations of such a society. Who has the ability to code these DAOs? An emerging class of capitalist technocrats? And how will material property be secured in the DAS? While legal scholars have noted that DAOs "have absolute sovereignty over their own resources" (De Filippi 2014a, par. 26), there is little discussion about how this relates to material property (e.g., land). The only solution that seems likely is either the use of already-existing states or other forms of private authority to protect material property while the "techno-leviathan" protects various forms of digital property (including financial forms such as debt, e.g.). Far from liberating us from the "terrible arc of the political", (Thiel as cited in Frank 2015, p. 27), however, this scenario seems more oppressive than ever. Many commentators have already criticized the increasing use of digital rights management (DRM) software to restrict access and control to products that could be replicated without any further additional cost (Teixeira and Rotta 2012). As O'Dwyer (2015, par.

\footnotetext{
${ }^{17}$ Kostakis and Giotitsas $(2014,437)$ make similar comments about Bitcoin, noting that "the code is in charge instead of central banks but as Lessig (2006) puts it, on the Internet the "code is law", thus pointing out the politicalness that is imbued in each piece of software. In the real world, the law enables banks to mediate credit transactions between various parties. The law ensures the credibility of contracts, protects property rights, and regulates money circulation (Lessig, 2006). Whereas in the digital world, according to Lessig (2006), code assumes this role and defines what users can and cannot do. Therefore Bitcoin as a piece of software is imbued with ideas drawn from a certain political framework."

${ }_{18}$ For example, Bloch (1964) provides a wealth of historical evidence on the different forms of property and contract in feudal society.

${ }^{19}$ As Teeple $(2005,33)$ notes: "The set of rights or property relations that characterize a social formation find their source in the social division of labour. They reflect the ways in which people produce and distribute the means of their subsistence. The inequalities inherent in a social formation and the social conflict that arises from the division of labour, as well as the attendant power relations are reflected in the nature and structure of the system of rights." In stateless social formations property relations will be informal or customary. In societies with a state, they will be formal and legally enforceable.

${ }^{20}$ As Wood $(2002,171)$ notes: "Although capitalism did not give rise to the nation state, and the nation state did not give rise to capitalism, the social transformations that brought about capitalism, with its characteristic separation of economic and political spheres, were the same ones that brought the nation state to maturity."
} 
16) notes, this could be even worse in the DAS as a result of artificial scarcity and new methods of control connected to smart property: "Property doesn't disappear, but instead it is enforced and exercised in different ways. If rights were previously exercised through norms, laws, markets and architectures, today they are algorithmically inscribed in the object." Can you imagine a world where even the most basic property relations are mediated by similar types of technologies? Surely, this would be a disaster for the vast majority of the world's subordinate classes who have nothing but their own labour power to exchange.

\section{The Concentration and Centralization of Capital}

The second issue that I want to deal with is the tendency toward the concentration and centralization of capital, and the extent to which Bitcoin 2.0 tech might make possible a society that is, as Fraser (2014) calls it: "commodities all the way down."

As Marx (1991) accurately notes, capital has an inborn tendency to concentrate and centralize. In the context of capitalist competition and accumulation, there emerge increasing levels of privately held capital. This is simply the concentration of capital in greater and greater amounts as it is reinvested. Since the total social capital is split amongst many individual capitals, however, the concentration of capital also leads to its centralization in the hands of a decreasing number of capitalists through competition. As Marx $(1991,777)$ puts it: "capital grows to a huge mass in a single hand in one place, because it has been lost by many in another place."

With the hindsight that late capitalism offers us, the reality of this phenomenon is increasingly clear. Through the early period of capitalist development, through the rise of imperialism and monopoly capital in the late nineteenth century, capital has become increasingly concentrated and centralized, existing today in the form of the transnational corporation (TNC). The amount of capital centralized and concentrated at this level is truly staggering. Recent research by a group of systems theorists at the Swiss Federal Institute of Technology shows that there are 1318 core TNCs with interlocking directorships, making up 80 percent of global operating revenues. ${ }^{21}$ In their attempt to disentangle this web, the researchers also found that "nearly 4/10 of the control over the economic value of TNCs in the world is held, via a complicated web of ownership relations, by a group of 147 TNCs in the core, which has almost full control over itself" (Vitali et al. 2011, 6). Consisting mainly of major global financial institutions-e.g., Goldman Sachs Group, JP Morgan Chase, Barclays Bank-this 'superentity' of TNCs reveals not only the hegemonic position of financial capital today, but also, the extent to which a relatively virtual form of capital is concentrated and centralized at the global level.

As noted by many authors, the earlier centralization and concentration of capital was part and parcel of the consolidation of the nation-state and the imperialist stage of capitalism (Brewer 2002; Robinson 2004; Teeple 2000). More recently, however, this growth has contributed to the emergence of non-national state forms that protect the rights of capital over multiple jurisdictions: trade agreements like CAFTA, NAFTA, WTO, and those currently being negotiated like the Trans-Pacific Partnership agreement (TPP) and the Trans-Atlantic Trade and Investment Partnership (also known as the Transatlantic Free Trade Area, or TAFTA) all function to "liberate transnational capital from the limitations of majoritarian politics" (Clarkson and Wood, 2010, 69). They do this primarily by giving corporations (usually foreign) the right to secretly sue national or subnational governments for policy changes that negatively impact the accumulation of capital.

Closely linked with globalization and the rise of financial power, this emerging nonnational state has greatly reduced the prospects for (liberal) democracy by pitting national rights against an emerging framework of global rights (for capital). And while many DAS supporters claim that Bitcoin 2.0 tech will work to reduce the power of large financial firms (Allison 2015a; Jaipuria 2015), these are the very firms that seem most interested in the technol-

\footnotetext{
${ }^{21}$ Although the firms themselves only represent 20 percent of global operating revenues, through shares they collectively own the majority of the world's largest blue chip and manufacturing firms, which represents a further 60 percent of global revenues.
} 
ogy (Popper 2015). Huge financial firms such as Deloitte and Goldman Sachs are already investing time and resources into the development of Bitcoin 2.0 tech with an eye towards using them to cut down on transaction costs, and further escape national-level regulation (Allison 2015b; Smith IV 2015). And not only this, they are collaborating so as to create a standardized system to buy and sell complicated assets:

Because any innovation in this area would require the cooperation of multiple banks, the banks have had joint meetings to discuss how they could work together, often led by outside start-ups looking to provide the software (Popper 2015, par. 26).

If we treat the DAS as an extension of this general trend-i.e. the removal of barriers to exchange worldwide in accordance with the growth of capital-then the prospects for protecting commons of any sort become increasingly dire. As Harvey $(2005,165)$ notes: "commodification presumes the existence of property rights over processes, things, and social relations, that a price can be put on them, and that they can be traded subject to legal contract." By allowing for the development of digital contracts in such a way as DAS supporters suggest, we provide the enabling framework for the digital rule of capital: the total commodification of global society.

Indeed, De Filippi (2014a, par. 35) has already noted that if such technologies were taken over by big corporations, financial institutions, or the state, it could "lead to the establishment of a totalitarian society that is (almost exclusively) regulated by self-enforcing contracts, which establish the rules that everyone must abide by, without any constitutional constraints." The point is, however, that this is already happening! Financial institutions are some of the largest investors in Bitcoin 2.0 tech, and there is nothing that suggests that capital as a whole would not benefit immensely from the predominance of this technology, which could feasibly allow certain accumulation activities to operate outside the sphere of national legal regulation and territorial space. Taken to its full extension, this might lead to entire territories that could one day be fully managed by DAOs. One only has to look at the already-existing "special economic zones" that have been created to escape national laws and regulations. ${ }^{22}$

This scenario reminds me of Marge Piercy's (1993) novel, He, She and It, in which large corporations operate autonomous political zones. In the book, whole populations grow up, work, and die, within the corporation, fully subject to that particular corporation's law and rules of conduct-outside of these zones, and few other anarchist holdouts, the environment has been turned into a wasteland. While this example is science fiction, it is certainly a real possibility given the way in which Bitcoin 2.0 tech is proposed to work. In saying this, I do not want to suggest that I am some sort of luddite, but rather, that if the technology works as claimed, this must be considered as one of a few likely outcomes-that property relations become increasingly denationalized in such a way as to allow the private authority of capital to reign across the globe. ${ }^{23}$ In this, I agree with De Zayas (as cited in Inman 2015, par. 5) when he says: "we don't want a dystopian future in which corporations and not democratically elected governments call the shots. We don't want an international order akin to postdemocracy or post-law." While the nation-state remains a bundle of class contradictions it is still, to this point, the most powerful mechanism that the world has seen for achieving social rights. To simply dispose of it would likely set subordinate classes back hundreds of years.

\section{Automation}

The third real world issue that I want to deal with is that of automation. Many DAS supporters perceive this recent trend as the basis for a future world in which digital corporations manage totally automated production units (e.g., factories). Some even see this as moving us away

\footnotetext{
${ }^{22}$ A report by the World Bank (Farole 2010) notes that by 2006 there were 3500 special economic zones in 130 countries. While many are in developing countries, there are significant amounts in advanced capitalist countries as well.

${ }^{23}$ As Sassen $(2003,2)$ notes, denationalization refers to processes that do no scale at the global level, but similarly "involve transboundary networks and formations connecting multiple local or 'national' processes and actors, or involve the recurrence of particular issues or dynamics in a growing number of countries."
} 
from capitalism proper, and toward a post-capitalist society of the collaborative commons in which everything is 'open source' (e.g., Dew 2015; Rifkin 2014).

What l'd like to do here is highlight the confusion over how Bitcoin 2.0 tech might operate within an already-existing capitalist mode of extraction, and why this process is not likely to lead to the fully-automated leisure society that DAS supporters hope. For example, Rifkin's $(2014,19)$ book, Zero Marginal Cost Society, stresses the idea that increasing automation will give way to more 'open' societies rooted in "open-source innovation, transparency, and the search for community." The logic behind such thinking is that capitalism's laws of motion will lead to both productivity increases and marginal cost decreases: when marginal cost (the cost of producing additional units of product) approaches zero, so too does profit these authors claim, since marginal cost is the point at which profit is made. Dew (2015, para 3) writes that we already see the results of this "wreaking havoc across several media industries such as entertainment, communications and publishing, as more and more content continues to be shared and made freely available across digital, collaborative networks."

While this may be true to some extent, there are a multitude of counter-examples-even in the very fields that Dew refers to as having been made redundant by decreasing marginal cost. Teixeria and Rotta $(2012,456-457)$, for instance, argue instead that contemporary capitalism is increasingly reliant on the production of valueless knowledge commodities, which are "privatized ideas, commodified knowledge, know-how, information, and instructions" that only employ labour for first-time production, and not continued re-production. Profit, in this instance, is secured merely by ownership, similar to a form of rent. In this context, it is questionable how a zero marginal cost society might come to exist while capitalism, with its giant corporate monopolies, are left intact. As noted by Taafe (2014, par. 26) in his review of Rifkin's book, there is a lot of discussion about the "Internet of Things," but no discussion of the transnational conglomerates that only invest and promote "products if there is profit in it." And there is little discussion about the fact that, as Bauwens and Kostakis $(2014,357)$ note, many TNCs appropriate "free software code for profit maximization and capital accumulation."

Indeed, a quick glance at who is developing automation technologies should give any reader pause for concern. In referring to Germany, Oberhaus $(2015$, par. 21, 27) notes that "the main impetus behind the ramped up industrialization [...] lies not so much with the consumer, but the potential benefits to multinational industrialists that will be its earliest adopters." Siemens AG, the largest engineering company in Europe, already produces automated machines for other companies, such as BMW and Bayer, using machines "which are themselves nearly entirely automated." Similarly, Amazon's warehouses are already staffed almost entirely by autonomous robots, and the company is currently looking into using flying drones for delivery purposes (Bensinger 2013). And in my own country of Canada, large oil firms are talking about how autonomous machines might transform the Alberta oil industry (Snyder 2015).

While it is still very early, the choice of Ethereum for IBM and Samsung's proof of concept for the 'Internet of Things' suggests that Bitcoin 2.0 tech will increasingly be used to automate the management function of robotic systems (Higgins 2015). As a result, many DAS supporters seem to believe that this technology will move us toward a world of automatic luxury. Indeed, it is not uncommon to find DAS supporters quoting Keynes $(2009,365)$ about how automation will allow us "to devote our further energies to non-economic purposes."

The great irony, of course, is that since Keynes' time, people work more than ever; automation has not lessened our working day, but rather, increased it. And furthermore, the increasing use of this technology in the production and service sectors means greater unemployment for the majority of the people on earth, or-perhaps more likely - the further proliferation of what David Graeber (as cited in Jeffries, 2015) refers to as "bullshit jobs" (see also, Dyer-Witheford, 2015). In such a world where "code is law" (Lessig 2000), it is not clear how automation will help liberate the world's subordinate classes. Instead, it appears that it will chain us ever tighter to capital's grip, subject to new forms of rentier activity. This seems especially true considering that most of the innovation that supports the DAS has to do with financial activities (Vigna and Casey 2015; Jaipuria 2015). Not only does Ethereum's team 
consist of two former Goldman Sachs employees, but Goldman has also invested $\$ 50$ million in the blockchain startup, Circle (Smith IV 2015). While Buterin (2015) claims that blockchains will make financial activities more transparent, it is not clear how they will reduce the social power of large financial TNCs, and the production firms linked to them.

\section{Conclusion}

Outside of the real world issues that I have examined, there is good reason to question the utopian narrative of the DAS. While the example of a washing machine ordering its own detergent is sufficiently domestic to obscure other uses of this technology, it is important that we recognize the destructive potential. With the coming of autonomous machines, we might soon live in a world where drones hire other machines for military purposes, or where in-body nano-technology autonomously negotiates with other technology outside your body (and perhaps, without our consent). Indeed, prominent individuals in the science and tech industry such as Stephen Hawking, Elon Musk, and Steve Wozniak, have already called for a ban on "offensive autonomous weapons" (Asaro 2015, par. 1).24 There is certainly no denying the potential of Bitcoin 2.0 tech, but it is this dark side that concerns me because it is necessarily opaque and hard to predict. Taken to its logical conclusion, however, the DAS can only appear as a utopia if one has totally expunged power and coercion from their analysis of social reality.

This is not to suggest, however, that all supporters of the DAS share this libertarian vision. There are many individuals who believe that Bitcoin 2.0 tech might better protect "the perimeter of the commons" by "empowering commoners to decide their own fate" (Bollier 2015, par. 21; see also, Clippinger and Bollier 2014). While there is no techno fix to the inherent contradictions of the capitalist mode of extraction, Bollier (2015, par. 22) notes that this technology could be used to leapfrog "over some of the dysfunctional politics and bureaucratic treachery that is rife in conventional institutions." Furthermore, Bauwens and Kostakis (2014) note that many of these technologies are able to scale up and down, making it possible to create distributed collaborative organizations (or 'open co-operativism' as they call it) that could be used to help smaller, regional areas protect their own commons-whether they be in the form of healthcare, education, water, air, internet, knowledge, and so on.25 In other words, we might be able to use DAOs to automatically manage common property resources-and without many of the problems typically associated with those regimes.

While this world is still far off, I agree with Bollier (2015, par. 22) that it "is a rich horizon worth exploring." But I think that we can only explore this rich horizon if we expunge ourselves (and the technology itself) from the type of thinking that views that state as an unnatural outgrowth whose only function is to restrict our inherent propensity to exchange. This view not only neglects that most technological innovation is state driven (Mazzucato 2014), but that the state can also be used to protect certain things from commodification, thus guaranteeing some of our freedoms against the tyranny of the market. Indeed, as Franklin (1999, 100) notes,

what turns the promised liberation into enslavement are not the products of technology per se $[\ldots]$ but the structure and infrastructures that are put in place to facilitate the use of these products and to develop dependency on them.

\footnotetext{
${ }^{24}$ Interestingly, "in a political loop-the-loop, a bill in North Dakota originally intended to limit the power of police drones actually permits unmanned aerial vehicles to use rubber bullets, pepper spray, tear gas, sound cannons, and Tasers" (Staedter 2015, par. 1).

${ }^{25}$ Frank $(2015,36)$ provides some further examples: "A group of friends or strangers, distributed throughout a neighbourhood or around the world, could set up a mutual-aid society without involving an insurance company. Each person would pay into a contract that would automatically release money to an injured or unemployed party when certain mutually agreed-upon conditions were met. This group might get more ambitious and create a digital community currency, with units distributed to all members on an egalitarian basis. They might build a digital voting system; the blockchain would guarantee transparency. If these experiments worked, the group could vote to accept new members, which would make the mutual-aid system more robust and the community currency more useful. As real and virtual imbricated further, these modest cooperative entities could and would scale up."
} 
To make certain that Bitcoin 2.0 tech provides the basis for progressive human development, we must ensure that it is used to secure our social rights, as opposed to a means of avoiding the state by escaping to digitally-mediated private spaces. Indeed, as Harvey (2015, par. 33) notes, it is important that people on the left take this technology seriously to "make sure this is not orchestrated as a right-wing gesture as happens with something like Bitcoin." As he continues: "Is there a way where we on the left can construct an alternative monetary system, which is actually much more democratic and much more socially constructed?" Only time will tell. But what is certain is that liberation will not come from a world subsumed by exchange relations, as many DAS supporters currently claim. It is in this sense that we must, as Franklin $(1999,133)$ writes, "protest until there is change in the structures and practices of the real world of technology, for only then can we hope to survive as a global community."

\section{References}

Alchemi. 2015. We Talk, Share, Create, Exchange, and Resolve: Decentralized Autonomous Society. Let's Talk Bitcoin. Accessed April 30. https://letstalkbitcoin.com/blog/post/we-talk-share-createexchange-resolve-decentralized-autonomous-society.

Allison, lan. 2015a. Bitcoin's Smart Sibling Ethereum Is 'the Only Game in Town' for Banks to Build Blockchains. International Business Times UK. July 27, 2015. http://www.ibtimes.co.uk/bitcoinssmart-sibling-ethereum-only-game-town-banks-build-blockchains-1512726.

Allison, lan. 2015b. Deloitte Is Delving into Ethereum, Eris and Ripple. International Business Times UK. August 14. http://www.ibtimes.co.uk/deloitte-delving-into-ethereum-eris-ripple-1515494.

Asaro, Peter. 2015. Ban Killer Robots before They Become Weapons of Mass Destruction. August 7. http://www.scientificamerican.com/article/ban-killer-robots-before-they-become-weapons-of-massdestruction/.

Bauwens, Michel, and Vasilis Kostakis. 2014. From the Communism of Capital to Capital for the Commons: Towards an Open Co-Operativism. tripleC: Communication, Capitalism \& Critique. Open Access Journal for a Global Sustainable Information Society 12 (1): 356-61.

Bensinger, Greg. 2013. Before Amazon's Drones Come the Robots. Wall Street Journal, December 9 , sec. Tech. http://www.wsj.com/articles/SB10001424052702303330204579246012421712386.

Bloch, Marc. 1964. Feudal Society. Phoenix Books. Chicago: University of Chicago Press.

Bollier, David. 2015. The Blockchain: A Promising New Infrastructure for Online Commons. News and Perspectives on the Commons. April 4, 2015. http://bollier.org/blog/blockchain-promising-newinfrastructure-online-commons.

Bookchin, Murray. 2015. The next Revolution: Popular Assemblies and the Promise of Direct Democracy, ed. Debbie Bookchin, and Blair Taylor. London; New York: Verso.

Brewer, Tony. 2002. Marxist Theories of Imperialism: A Critical Survey. London; New York: Routledge.

Burkitt, lan. 2008. Social Selves: Theories of Self and Society. $2^{\text {nd }}$ edn. London: SAGE Publications Ltd.

Buterin, Vitalik. 2013. Bootstrapping A Decentralized Autonomous Corporation: Part I. Bitcoin Magazine. September 19, 2015. https://bitcoinmagazine.com/7050/bootstrapping-a-decentralizedautonomous-corporation-part-i/.

Buterin, Vitalik. 2014. White Paper: Ethereum/wiki. GitHub. https://github.com/ethereum/wiki.

Buterin, Vitalik. 2015. Triple Canopy—Decentralized Autonomous Society by Vitalik Buterin with Sam Frank. Triple Canopy. February 24, 2015.

http://www.canopycanopycanopy.com/contents/decentralized-autonomous-society-transcript.

Castells, Manuel. 2010. The Rise of the Network Society. $2^{\text {nd }}$ edn. The Information Age: Economy, Society, and Culture, v. 1. Chichester, West Sussex; Malden, MA: Wiley-Blackwell.

Clarkson, Stephen, and Stepan. Wood. 2010. A Perilous Imbalance: The Globalization of Canadian Law and Governance. Vancouver: UBC Press.

Clippinger, John, and David Bollier, eds. 2014. From Bitcoin to Burning Man and Beyond: The Quest for Identity and Autonomy in a Digital Society. Amherst, Massachusetts: ID3.

Colony. 2015. http://colony.io.

De Filippi, Primavera. 2014a. Ethereum: Freenet or Skynet? | Guerrilla Translation! http://www.guerrillatranslation.org/2014/11/20/ethereum-freenet-or-skynet/.

De Filippi, Primavera. 2014b. "Bitcoin: A Regulatory Nightmare to a Libertarian Dream." Internet Policy Review 3 (2). http://policyreview.info/articles/analysis/bitcoin-regulatory-nightmare-libertariandream. 
De Filippi, Primavera, and Luca Belli. 2012. Law of the Cloud v Law of the Land: Challenges and Opportunities for Innovation. European Journal of Law and Technology 3 (2). http://ejlt.org/article/view/156/242.

De Filippi, Primavera, and Raffaele Mauro. 2014. Ethereum: The Decentralised Platform That Might Displace Today's Institutions. Internet Policy Review.

De Sousa Santos, Boaventura. 2004. The World Social Forum: Toward a Counter-Hegemonic Globalisation (part I). In World Social Forum: Challenging Empires.

Dew, Chris. 2015. Post-Capitalism: Rise of the Collaborative Commons. Medium. https://medium.com/@cjdew/post-capitalism-rise-of-the-collaborative-commons-62b0160a7048.

Dodd, Nigel. 2014. The Social Life of Money. Princeton, New Jersey: Princeton University Press.

Dodd, Nigel. 2015. Bitcoin, Utopianism and the Future of Money / King's Review-Magazine. March 14, 2015. http://kingsreview.co.uk/magazine/blog/2015/03/14/bitcoins-utopianism-and-the-future-ofmoneyl.

Durkheim, Émile. 1973. Émile Durkheim on Morality and Society, Selected Writings, ed. Robert N. Bellah. Chicago: University of Chicago Press.

Dyer-Witheford, Nick. 2015. Cyber-Proletariat: Global Labour in the Digital Vortex. Pluto Press.

Elias, Norbert. 2000. The Civilizing Process. $2^{\text {nd }}$ edn. Oxford; Malden, Mass: Wiley-Blackwell.

Farole, Thomas. 2010. Special Economic Zones: Performance, Policy and Practice- with a Focus on Sub-Saharan Africa. Washington, D.C.: International Trade Department, World Bank.

Finley, Klint. 2014. Out in the Open: Teenage Hacker Transforms Web Into One Giant Bitcoin Network. WIRED. January 27, 2015. http://www.wired.com/2014/01/ethereum/.

Franklin, Ursula M. 1999. The Real World of Technology (CBC Massey Lectures Series) Revised Edition. $2^{\text {nd }}$ edn. Toronto, Ontario: Berkeley, CA: House of Anansi Press.

Frank, Sam. 2015. Come With Us If You Want to Live. Harper's Magazine, January 2015. http://harpers.org/archive/2015/01/come-with-us-if-you-want-to-live/.

Fraser, Nancy. 2014. Can Society Be Commodities All the Way down? Post-Polanyian Reflections on Capitalist Crisis. Economy and Society 43 (4): 541-58.

Freud, Sigmund. 2010. Civilization and Its Discontents. Martino Fine Books.

Friedman, Milton. 1962. Capitalism and Freedom. Chicago: University of Chicago Press.

Hajdarbegovic, Nermin. 2014. Ethereum's Vitalik Buterin Wins World Technology Network Award. CoinDesk. November 19, 2015. http://www.coindesk.com/ethereums-vitalik-buterin-wins-worldtechnology-network-award/.

Harvey, David. 2005. A Brief History of Neoliberalism. Oxford; New York: Oxford University Press.

Harvey, David. 2015. David Harvey: Looking Toward a Moneyless Economy and Sleeping Well at Night. Truthout. http://www.truth-out.org/news/item/28879-looking-toward-a-moneyless-economyand-sleeping-well-at-night.

Higgins, Stan. 2015. IBM Reveals Proof of Concept for Blockchain-Powered Internet of Things. CoinDesk. January 17, 2015. http://www.coindesk.com/ibm-reveals-proof-concept-blockchainpowered-internet-things/.

Inman, Phillip. 2015. UN Calls for Suspension of TTIP Talks over Fears of Human Rights Abuses. The Guardian. May 4, 2015. http://www.theguardian.com/global/2015/may/04/ttip-united-nationshuman-right-secret-courts-multinationals.

Jaipuria, Tanay. 2015. The Unbundling of Commercial Banks. Medium. https://medium.com/@tanayj/the-unbundling-of-commercial-banks-995a8fcd3aec.

Jeffries, Stuart. 2015. David Graeber: 'So Many People Spend Their Working Lives Doing Jobs They Think Are Unnecessary.' The Guardian. Accessed May 31.

http://www.theguardian.com/books/2015/mar/21/books-interview-david-graeber-the-utopia-of-rules.

Kang, Matthew. 2014. Bank of Canada Looking into Issuing Digital Currency. November 14. http://www.cbc.ca/1.2834759.

Karlstrøm, Henrik. 2014. Do Libertarians Dream of Electric Coins? The Material Embeddedness of Bitcoin. Distinktion: Scandinavian Journal of Social Theory 15 (1): 23-36.

Keynes, John Maynard. 2009. Essays in Persuasion. New York: Createspace.

Kosner, Anthony. 2014. Tech 2015: Block Chain Will Break Free From Bitcoin To Power Distributed Apps. Forbes. http://www.forbes.com/sites/anthonykosner/2014/12/31/tech-2015-block-chain-willbreak-free-from-bitcoin-to-power-distributed-apps/.

Kostakis, Vasilis, and Chris Giotitsas. 2014. The (A) Political Economy of Bitcoin. tripleC: Communication, Capitalism \& Critique 12 (2): 431-40. 
Larimer, Stan. 2013. Bitcoin and the Three Laws of Robotics. Let's Talk Bitcoin. September 14, 2015. https://letstalkbitcoin.com/blog/post/bitcoin-and-the-three-laws-of-robotics.

Lessig, Lawrence. 2000. Lawrence Lessig on the Increasing Regulation of Cyberspace | Harvard Magazine Jan-Feb 2000. http://harvardmagazine.com/2000/01/code-is-law-html.

Macpherson, C. B. 1965. The Real World of Democracy. CBC Massey Lecture Series. Toronto: Canadian Broadcasting Corp.

Macpherson, C. B. 1973. Democratic Theory: Essays in Retrieval. Oxford: Clarendon Press.

Macpherson, C. B. 2010. The Political Theory of Possessive Individualism: Hobbes to Locke. Reprint edition. Don Mills, Ont: OUP Canada.

Mandeville, Bernard. 2007. The Fable of the Bees: Or, Private Vices, Publick Benefits, ed. Phillip Harth. Reprint edition. Penguin.

Marx, Karl. 1991. Capital: Volume 1: A Critique of Political Economy. Reprint edition. Penguin Classics.

Mason, Paul. 2015. Can a Bitcoin-Style Virtual Currency Solve the Greek Financial Crisis? The Guardian. February 22, 2015. http://www.theguardian.com/commentisfree/2015/feb/22/can-a-paralleldigital-currency-solve-the-greek-financial-crisis.

Mazzucato, Mariana. 2014. The Entrepreneurial State: Debunking Public vs. Private Sector Myths. Revised edn. Anthem Frontiers of Global Political Economy. London; New York: Anthem Press.

Meltzer, Tom. 2014. Robot Doctors, Online Lawyers and Automated Architects: The Future of the Professions? The Guardian, June 15, sec. Technology. http://www.theguardian.com/technology/2014/jun/15/robot-doctors-online-lawyers-automatedarchitects-future-professions-jobs-technology?curator=MediaREDEF.

Nakamoto, Satoshi. 2008. Bitcoin: A Peer-to-Peer Electronic Cash System. Consulted 1 (2012): 28.

O'Dwyer, Rachel. 2015. The Revolution Will (not) Be Decentralised: Blockchains. Commons Transition. June 11, 2015. http://commonstransition.org/the-revolution-will-not-be-decentralisedblockchains/.

Oberhaus, Daniel. 2015. This Is What the Fourth Industrial Revolution Looks Like. Motherboard. April 13. http://motherboard.vice.com/read/life-after-the-fourth-industrial-revolution.

Osborne, C. 2014. Thoughts on Bitcoin Regulation from 50+ Bitcoin Experts. Founders Grid. January 23, 2015. http://foundersgrid.com/bitcoin-regulation.

Patron, Travis. 2014. The Bitcoin Revolution: How Digital Currency Is Disrupting the World Economy. Diginomics.

Perlberg, Steven. 2013. BERNANKE: Bitcoin 'May Hold Long-Term Promise.' November 18, 2015. http://widget.perfectmarket.com/wwwbusinessinsider/tbbfAd.html?wid=tbx-text-links- h\&wmd=textlinks-h\&wpl=TBXbackfill640x110\&ppn=tbx-network.

Piercy, Marge. 1993. He, She and It. Reprint edition. New York, N.Y: Fawcett.

Polanyi, Karl. 2002. The Great Transformation: The Political and Economic Origins of Our Time. 2nd edition. Boston, MA: Beacon Press.

Pollen, Satoshi. 2013. Bitcoin Is A Transition Technology. https://www.youtube.com/watch?v=i5VVmTI9F9s\&feature=youtube gdata player.

Popper, Nathaniel. 2015. Bitcoin Technology Piques Interest on Wall St. The New York Times, August 28, 2015. http://www.nytimes.com/2015/08/31/business/dealbook/bitcoin-technology-piquesinterest-on-wall-st.html.

Rand, Ayn. 1964. The Virtue of Selfishness: Fiftieth Anniversary Edition. 50th edition. New York: Signet.

Reich, Charles. 1964. The New Property. The Yale Law Journal 73 (5): 733-87.

Rifkin, Jeremy. 2014. The Zero Marginal Cost Society: The Internet of Things, the Collaborative Commons, and the Eclipse of Capitalism. New York: Palgrave Macmillan.

Robinson, Chris. 2015. THE DECENTRALIZATION MEGA-TREND AND THE FUTURE OF THE SPECIES. http://n-o-d-e.net/post/109307736436/the-decentralization-mega-trend-and-the-future-of.

Robinson, William I. 2004. A Theory of Global Capitalism: Transnational Production, Transnational Capitalists, and the Transnational State. Baltimore: Johns Hopkins University Press.

Sassen, Saskia. 2003. Globalization or Denationalization? Review of International Political Economy 10 (1): 1-22.

Schneider, Nathan. 2015. Code Your Own Utopia: Meet Ethereum, Bitcoin's Most Ambitious Successor | Al Jazeera America. Accessed May 21. http://america.aljazeera.com/articles/2014/4/7/codeyour-own-utopiameetethereumbitcoinasmostambitioussuccessor.html. 
Scott, Brett. 2014. Visions of a Techno-Leviathan: The Politics of the Bitcoin Blockchain. EInternational Relations. http://www.e-ir.info/2014/06/01/visions-of-a-techno-leviathan-the-politics-ofthe-bitcoin-blockchain/.

Simmel. 1972. Georg Simmel on Individuality and Social Forms. New edition edition. Chicago: University of Chicago Press.

Smith, Adam. 2001. Wealth of Nations. Hayes Barton Press.

Smith IV, Jack. 2015. It's Happening: Goldman Sachs Just Dropped $\$ 50$ Million Into a Bitcoin Startup. Observer. April 30. http://observer.com/2015/04/its-happening-goldman-sachs-just-dropped-50million-into-a-bitcoin-startup/.

Snyder, Jesse. 2015. How the 'rise of the Machines' Will Transform Oil and Gas. Alberta Oil Magazine | Canada's Leading Source for Oil and Gas News. March 16. http://www.albertaoilmagazine.com/2015/03/rise-of-the-machines/.

Staedter, Tracy. 2015. "North Dakota Legalizes Armed Drones." DNews. August 26. http://news.discovery.com/tech/gear-and-gadgets/north-dakota-legalizes-armed-drones150826.htm.

Szabo, Nick. 1997. The Idea of Smart Contracts. http://www.firstmonday.dk/issues/issue2 9/szabo/index.html.

Taafe, Peter. 2014. A 'Third Industrial Revolution': Review of The Zero Marginal Cost Society by Jeremy Rifkin. Socialist Alternative. http://www.socialistalternative.org/2014/11/03/third-industrialrevolution-review-the-marginal-cost-society-jeremy-rifkin/.

Taylor, Charles. 2004. Modern social imaginaries. Durham: Duke University Press.

Teeple, Gary. 2000. Globalization and the Decline of Social Reform into the Twenty-First Century. Aurora, Ont.: Garamond Press.

Teeple, Gary. 2004. The Riddle of Human Rights. Amherst, N.Y.: Humanity Books.

Teixeira, Rodrigo Alves and Tomas Nielsen Rotta. 2012. Valueless Knowledge-Commodities and Financialization: Productive and Financial Dimensions of Capital Autonomization. Review of Radical Political Economics 44 (4): 448-67.

The Ecologist. 1993. Whose Common Future?: Reclaiming the Commons : The Ecologist. Philadelphia: New Society Publishers.

The Fundamental Thesis Of The Network Society. 2015. Network Society Project. Accessed August 28, 2015. http://netsoc.org/thesis/.

Thorp, Noah. 2015. How Society Will Be Transformed By CryptoEconomics. Medium. https://medium.com/@noahthorp/how-society-will-be-transformed-by-crypto-economicsb02b6765ca8c.

United Nations Conference on Trade and Development. 2013. Recent Developments in Investor-State Dispute Settlement (ISDS): Updated for the Multilateral Dialogue on Investment, 28-29 May 2013.

Vigna, Paul, and Michael J. Casey. 2015. The Age of Cryptocurrency: How Bitcoin and Digital Money Are Challenging the Global Economic Order. New York: St. Martin's Press.

Vitali, Stefania, James B. Glattfelder, and Stefano Battiston. 2011. The Network of Global Corporate Control. PLoS ONE 6 (10): e25995. doi:10.1371/journal.pone.0025995.

Volpicelli, Gian. 2015. "Smart Contracts Sound Boring, But They're More Disruptive Than Bitcoin." Motherboard. http://motherboard.vice.com/read/smart-contracts-sound-boring-but-theyre-moredisruptive-than-bitcoin.

Wall Street, directed by Oliver Stone. 1987. Beverly Hills, C.A.: $20^{\text {th }}$ Century Fox Home Entertainment, 2006. DVD.

Winters, Jeffrey A. 2011. Oligarchy. Cambridge; New York: Cambridge University Press.

Wood, Ellen Meiksins. 2002. The Origin of Capitalism: A Longer View. London; New York: Verso.

\section{About the Author}

J.Z. Garrod

J.Z. Garrod is a PhD candidate in the department of Sociology and Anthropology at Carleton University. His current research focuses on globalization and the rise of non-national state forms. 